\title{
A competência percebida pelos alunos, as expectativas do professor e o desempenho académico: como se relacionam na disciplina de educação física?
}

\author{
José Henrique \\ Carlos Januário
}

https://doi.org/10.5628/rpcd.06.02.194
Universidade Técnica de Lisboa

Faculdade de Motricidade Humana

Portugal

\section{RESUMO}

A auto-percepção de competência influencia o interesse e a persistência do aluno na concretização da aprendizagem. $\mathrm{O}$ objectivo deste estudo analisa a relação entre o desempenho dos alunos, as expectativas dos professores e a competência percebida pelos alunos. O estudo é descritivo e a amostra é constituída por 10 professores e 186 alunos da $6^{\mathrm{a}}$ à $8^{\mathrm{a}}$ série do ensino fundamental brasileiro. O desempenho dos alunos foi medido através de testes, e a percepção pessoal do aluno e as expectativas do professor foram obtidas através da técnica de auto-relato. As estatísticas descritiva e inferencial permitiram a análise da congruência entre as variáveis em estudo. A competência percebida pelos alunos tem forte associação positiva, tanto com o seu desempenho, como com as expectativas do professor. Há uma expressiva correspondência entre as expectativas dos professores e o desempenho dos alunos. Os resultados demonstram a necessidade de aprofundar o estudo das expectativas do professor e os seus efeitos sobre o comportamento de ensino e a representação de competência formulada pelos alunos.

Palavras-chave: auto-percepção de competência, educação física escolar, pensamento do aluno, expectativas do professor, ensino.

\begin{abstract}
Pupil's self-perceived competence, teacher expectations, and academic performance: How do they relate in Physical Education?

Student's perceived competence influences interest and persistence in learning accomplishment. The aim of this study was to analyze the relationships among student performance, teachers' expectations and student's perceived competence. Having a descriptive approach, we sampled 10 teachers and $1866^{\text {nd }}$ to $8^{\text {nd }}$ grade students of the Brazilian educational system. Student performance was measured through tests, and the student's personal perception and teacher's expectation were picked up through self-report measures. Descriptive and inferential statistics allowed the analysis of the congruence among the variables in study. Student's personal perception has strong association with student performance and teacher's expectations. The teachers' expectations corresponded meaningfully with the students' performance. The results demonstrate the need to deepen the study of the effects of teachers' expectations on the teaching behaviour and students' perceived competence.
\end{abstract}

Key Words: perceived competence, school physical education, pupil thinking, teacher's expectations, teaching. 


\section{INTRODUÇÃO}

$\mathrm{Na}$ actualidade, a combinação de diferentes paradigmas de investigação sobre o ensino responde a um desafio e a um apelo frequente e constante na literatura $(23,17)$, oferecendo a vantagem de ampliar o conhecimento sobre fenómenos caracterizados pela complexidade - pelo número de variáveis presentes e/ou pela variabilidade e diferenciação de cada variável. É sob este enfoque que, nos últimos anos, se tem verificado a multiplicação de estudos que se reportam à análise das acções de ensino, complementados pelo estudo das variáveis psicológicas de professores e alunos, aprofundando o conhecimento sobre o ensino e a aprendizagem com vista ao incremento da eficácia pedagógica. O aprofundamento das investigações tem mostrado quanto os processos psicológicos alimentam as acções de professores e alunos, bem como a relação pedagógica, surgindo mesmo como poderosos preditores dos eventos ocorridos no processo educativo.

Assim, a investigação sobre os processos de pensamento do professor (5) tem relevado a influência dos processos cognitivos dos professores sobre as suas acções de ensino. O modelo 'Pensamento e Acção do Professor' propõe a integração destes dois grandes domínios (Figura 1).

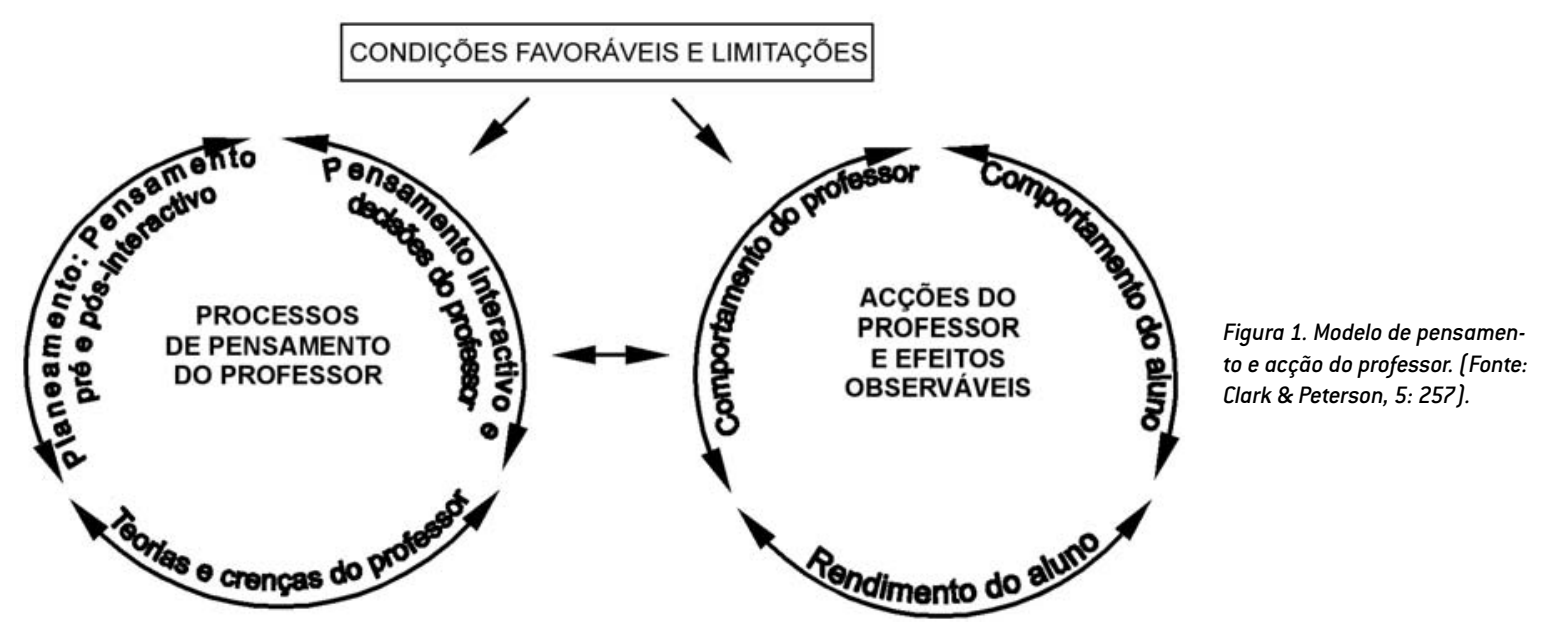

Segundo a teoria, o comportamento do professor, o comportamento do aluno e os resultados de aprendizagem influenciam-se mútua e reciprocamente. A apresentação no formato circular pretende dar sentido à inter-influência entre as componentes de cada dimensão do acto educativo. Deste modo, conceptualiza-se que os pensamentos e decisões dos professores interagem qualitativamente entre as fases interactiva, pré-interactiva e pós-interactiva de ensino. No âmbito da acção docente esta perspectiva assume a causalidade recíproca das interacções, i.e., o comportamento do professor afecta o comportamento do aluno que, em contrapartida, influencia o comportamento e as decisões do professor, bem como as próprias realizações. A influência entre as duas dimensões e respectivas componentes é concomitante e resulta em consequências directas para o ensino e para o desempenho académico. O modelo é rematado com referência aos aspectos com os quais os professores lidam no dia-a-dia da função docente e que, pela sua natureza, facilitam ou limitam a actuação profissional.

Da mesma forma, tem sido relevado o contexto psicológico do aluno e dos seus processos de pensamento. A pesquisa que considera central o pensamento discente evoca a importância desta variável para explicar o envolvimento do aluno no processo ensino-aprendizagem. A teoria enfatiza o papel das crenças, expectativas, motivações, atitudes e sentimentos como mediadores entre o ensino e a aprendizagem, assumindo que esta ligação pode ser esclarecida sob a perspectiva formulada pelos alunos $(9,8)$. 
Um conjunto considerável de pesquisas tem relevado a importância da percepção de competência do aluno no processo ensino-aprendizagem $(2,3,9,27,10$, 16). A percepção de competência tem constituído objecto de interesse das teorias da motivação devido à sua evidente influência sobre as capacidades volitivas do aluno, com reflexos sobre o seu envolvimento activo nas tarefas de aprendizagem (25). Para Bandura (1), um dos factores mais poderosos do autoconhecimento é a própria concepção de eficácia, pois o sentimento positivo acerca das capacidades próprias fomenta no aluno o interesse e a persistência para a concretização da aprendizagem. Na visão de alguns investigadores $(16,9)$, a forma como o aluno percebe a própria competência é mais importante do que aquela efectivamente dominada, quando se busca explicar a sua motivação e aprendizagem. Portanto, o sentido que os alunos conferem à própria capacidade de realização e os sentimentos positivos sobre a própria competência são condicionantes da efectiva participação no processo ensinoaprendizagem (29).

A percepção de competência do aluno é condicionada por factores sociais (professor, pais, colegas de classe), contextuais relativos ao próprio (género, idade ou estágio de desenvolvimento, orientação dos objectivos pessoais, habilidade real do aluno) e de ordem pedagógica (conteúdo, oportunidades, clima de aula) $(28,29,11,9,22,13,15,16)$. No processo ensino-aprendizagem a competência percebida pelo aluno é ainda influenciada pelo comportamento e expectativas do professor. As expectativas do professor sobre a habilidade dos alunos induzem ao comportamento de ensino que influencia e sustenta certos tipos de desempenho no aluno. É isso que nos ensina a profecia de auto-realização ou, como também é conhecida, a teoria do efeito pigmalião $(21,13,14)$.

De acordo com o modelo proposto por Martinek (13), as expectativas originam-se em consequência de impressões relacionadas com as características pessoais de professores e alunos ou da interacção de ambas $(13,15)$. O modelo assume que se o professor espera e encoraja um determinado nível de performance, o aluno perceberá e produzirá, assim, um rendimento compatível com o esperado pelo professor. Pimentel (20) constatou que os alunos eleitos pelos professores como mais e menos competentes mereceram tratamento diferenciado durante o ensino. Outro estudo (26) constatou que os alunos de alto rendimento pensaram receber expectativas mais altas de seus professores e mais oportunidades de escolhas que seus opostos. Enquanto as expectativas elevadas seriam bem acolhidas no ambiente de ensino, por projectarem atitudes positivas e, possivelmente, rendimentos compatíveis, as baixas expectativas perpetuariam o baixo rendimento sendo, por isso, preocupantes no meio educativo.

Parece não existir dúvida de que aquilo que o aluno pensa ser capaz de fazer, bem como aquilo que ele percebe que outras pessoas esperam que ele faça, influenciam a sua auto-confiança, as interacções na classe, a performance e a capacidade para aprender outras tarefas (15). Na investigação realizada por Bibik (2), a percepção de competência de $50 \%$ dos alunos foi concordante com as expectativas dos professores. Este facto, somado à evidência de tratamentos diferenciados para alunos com diferentes níveis de habilidade, levou a autora a concluir que a percepção de competência dos alunos foi influenciada pelas expectativas do professor. No estudo com alunos norte-americanos (29), a auto-avaliação de competência reportada pelos alunos apresentou relação positiva e significativa com as avaliações dos professores em turmas do $4^{\circ}, 8^{\circ}$ e $11^{\circ}$ anos de escolaridade.

Qualquer esforço científico comprometido em identificar factores que influenciam os sentimentos e crenças dos alunos é importante porque intenta trazer subsídios para a melhoria do ensino e a potencialização da aprendizagem. Com efeito, neste estudo, a competência percebida será compreendida pelo julgamento do próprio aluno sobre quanto ele se percebeu hábil na realização de uma tarefa desportiva ensinada nas aulas de educação física.

Se muito do que o aluno crê ser capaz de realizar é influenciado pelas expectativas do professor, então torna-se coerente estudarmos as realizações e percepções pessoais do aluno, com base no que os professores alimentam como expectativas. Pretendemos abordar esta questão, investigando a percepção de competência reportada pelos alunos em associação com o desempenho académico e as expectativas formuladas pelos professores. Assim, procuramos respostas para as seguintes questões: 
1. A competência percebida formulada pelos alunos é congruente com as expectativas dos professores? 2. Em que medida a competência percebida pelos alunos de alta e baixa percepção de competência e as expectativas dos professores correspondem ao desempenho dos alunos?

\section{METODOLOGIA}

Este estudo desenvolveu-se mediante um design descritivo visando caracterizar as variáveis em análise em relação aos sujeitos, ao ambiente e à realidade do ensino da educação física em escolas públicas brasileiras. Para a realização da pesquisa de campo foram cumpridos os procedimentos de autorização junto aos órgãos de gestão das redes de ensino, direcção das escolas, docentes, discentes e respectivos responsáveis.

\section{A unidade experimental de ensino}

A unidade experimental de salto em altura tesoura decorreu em ambiente real de ensino e foi composta por três aulas (uma aula semanal, com duração máxima de 50 minutos), com mais uma aula destinada à avaliação do desempenho final.

\section{Selecção da amostra}

A amostra é caracterizada como conveniente, pois a selecção obedeceu a critérios objectivos de inclusão desejáveis para o desenvolvimento da pesquisa (6, 4). Foram seleccionados 10 professores experientes $(\mathrm{M}=8$ e $\mathrm{F}=2)$ com base em critérios de experiência, biografia profissional e concordância em desenvolver a unidade experimental de ensino proposta. A idade dos professores variou entre 32 e 46 anos $(39.4 \pm 5)$ e o tempo de serviço entre 8 e 21 anos (14.8 \pm 4.5$)$. Os professores leccionaram turmas da $6^{\mathrm{a}}$ à $8^{\mathrm{a}}$ série do ensino fundamental em regime coeducacional, em nove escolas públicas do Estado do Rio de Janeiro.

A amostra de alunos emergiu de um quantitativo inicial de 363 alunos, seleccionados em função de (a) demonstrarem interesse em participar no estudo, (b) não terem vivenciado anteriormente o conteúdo desenvolvido na unidade experimental de ensino, (c) frequentarem integralmente as aulas e, (d) realizarem o teste final de desempenho. Assim, foram seleccionados 186 alunos $(\mathrm{M}=104$ e $\mathrm{F}=82)$, com idade entre 11 e 18 anos $(13.2 \pm 1,4)$.

\section{Procedimentos Expectativas dos professores}

Os professores foram previamente solicitados a indicar, nas suas turmas, os alunos que alcançariam alto e baixo desempenho na unidade de salto em altura tesoura; os alunos não indicados nestes grupos foram considerados medianos. Este procedimento permitiu conhecer as expectativas dos professores em relação aos seus alunos.

\section{Desempenho académico}

Os alunos foram avaliados mediante um teste na semana posterior à unidade experimental de ensino, realizado pelos professores nas aulas de educação física, respeitando o seguinte protocolo: os professores comunicaram à turma o objectivo e o protocolo da avaliação; realizaram uma demonstração do salto tesoura; não forneceram feedback, nem manifestaram comportamentos de incentivo, correcção ou crítica aos alunos; o primeiro salto foi realizado à altura de $60 \mathrm{~cm}$ para as meninas e $70 \mathrm{~cm}$ para os meninos, elevada em $5 \mathrm{~cm}$ a cada sequência; os alunos tiveram duas oportunidades para ultrapassar cada altura.

\section{Competência percebida pelos alunos}

Avaliada posteriormente aos testes de desempenho, por auto-relato em questionário, numa escala tipo Likert de cinco pontos (muito habilidoso, habilidoso, nem muito nem pouco habilidoso, pouco habilidoso, muito pouco habilidoso). Os alunos não comentaram as respostas entre si ou com o professor, a fim de evitar influências de outrem.

\section{Notas de campo}

As notas de campo foram recolhidas durante as aulas da unidade experimental de ensino e nos contactos mantidos com os professores, reflectindo algumas verificações contextuais no tocante ao comportamento de instrução do professor e ao clima relacional estabelecido com os alunos de alta e baixa expectativa de desempenho. A utilização desta técnica permitiu-nos obter informações que pudessem, de alguma forma, complementar e mesmo ajudar a explicar os restantes dados.

\section{Análise dos dados}

Utilizou-se a média, desvio-padrão e percentagem para caracterizar os sujeitos e as representações for- 
muladas por professores e alunos. Através do cálculo de quartis categorizou-se os pólos de expectativas docentes, de percepções discentes e de desempenho, em simultâneo.

A congruência entre a auto-percepção dos alunos e a expectativa dos professores, bem como a medida de correspondência destas variáveis com o desempenho, foram obtidas mediante o cruzamento das variáveis (crosstabulation) relativas aos professores, alunos (1x1) e resultados de desempenho ( $1 \times 1$ e $2 \times 1)$. A partir do cruzamento das variáveis, ascendeu-se às proporções produzidas pelas categorias (expectativas, percepções e desempenho) e classes (alto, médio e baixo) das variáveis.

A média de desempenho dos alunos foi comparada para cada nível de competência percebida e de expectativas docentes, bem como inter e intragrupos congruentes e incongruentes, utilizando-se para isso o teste $t$ de Student para diferença de médias. Por fim, o $r$ de Pearson forneceu o índice de correlação existente entre as variáveis estudadas. Para ambas as provas o nível de significância foi estabelecido em .05.

\section{RESULTADOS}

O primeiro procedimento, empregue no sentido de analisar a correspondência entre as expectativas dos professores e a percepção de competência dos alunos, verificou em que medida os alunos sobre os quais os professores alimentavam alta e baixa expectativa, também possuíam percepções correlatas a respeito da sua própria competência. Os professores listaram 46 alunos sobre os quais depositavam altas expectativas de desempenho. Dentre estes alunos, 78.3\% também reportaram alta competência percebida, i.e., estes alunos foram alvo de altas expectativas dos professores e se perceberam 'habilidosos' ou 'muito habilidosos'. Por outro lado, os professores manifestaram baixas expectativas sobre 39 alunos, mas apenas $25.6 \%$ destes apresentaram índices de baixa competência percebida, considerando-se 'pouco' ou 'muito pouco habilidosos'.

A Figura 2 resume os resultados obtidos relativos à ocorrência de congruência entre percepções dos alunos e expectativas dos professores. Na diagonal demarcada a sombreado encontra-se o resultado dos alunos que denominamos congruentes, pois a sua percepção de competência foi concordante com as expectativas do professor. Acima e abaixo da parte sombreada encontram-se os alunos cuja concordância não se verificou e, por isso, foram denominados incongruentes. Estes foram ainda classificados em incongruente-alto (acima da área sombreada), porque perceberam a sua habilidade acima do esperado pelo professor e, incongruente-baixo (abaixo da área sombreada), porque as suas percepções estiveram aquém das expectativas do professor.

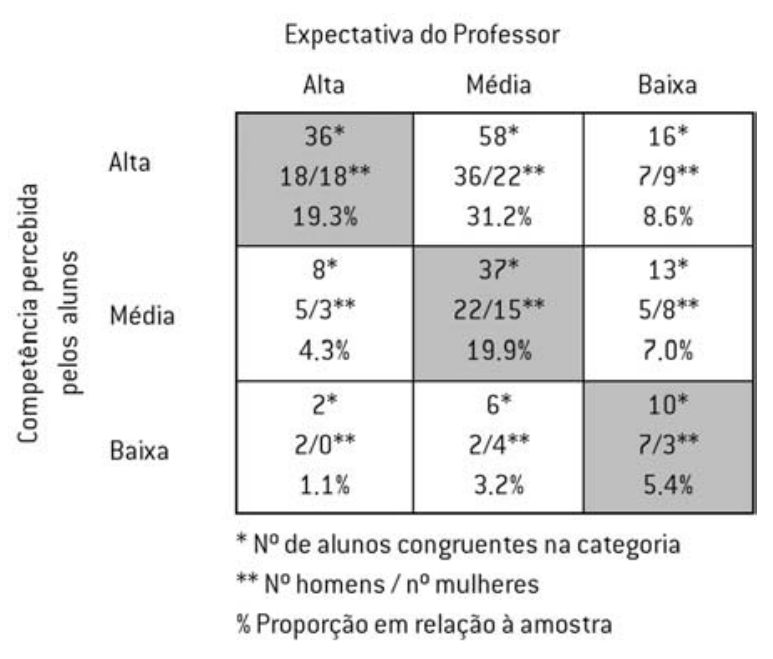

Figura 2. Congruência entre expectativa dos professores e a competência percebida pelos alunos.

Na Tabela 1 pode-se constatar que a percepção de competência de uma parcela considerável da amostra foi congruente com as expectativas projectadas pelos professores. Verifica-se que 83 alunos $(44.6 \%$ da amostra) perceberam a sua competência de forma congruente com as expectativas do professor, sendo 47 do género masculino (56.6\% do grupo congruente e $45.2 \%$ da amostra masculina) e 36 do género feminino ( $43.4 \%$ do grupo congruente e $43.9 \%$ da amostra feminina). 
Tabela 1. Composição dos grupos congruente e incongruente.

\begin{tabular}{|c|c|c|c|c|}
\hline Género & Congruência & N & $\begin{array}{l}\text { Composição } \\
\text { no grupo } \\
\text { congruente }\end{array}$ & $\begin{array}{l}\text { Composiçāo } \\
\text { no grupo } \\
\text { incongruente }\end{array}$ \\
\hline \multirow[t]{3}{*}{ Masculino } & Congruente & $\begin{array}{l}47 \\
{[25.3 \%]}\end{array}$ & $56.6 \%$ & . \\
\hline & Incongruente & $\begin{array}{l}57 \\
{[30.6 \%]}\end{array}$ & . & $55.3 \%$ \\
\hline & Total & $\begin{array}{l}104 \\
{[55.9 \%]}\end{array}$ & & \\
\hline \multirow[t]{3}{*}{ Feminino } & Congruente & $\begin{array}{l}36 \\
{[19.4 \%]}\end{array}$ & $43.4 \%$ & \\
\hline & Incongruente & $\begin{array}{l}46 \\
{[24.7 \%]}\end{array}$ & . & $44.7 \%$ \\
\hline & Total & $\begin{array}{l}82 \\
{[44.1 \%]}\end{array}$ & & \\
\hline \multicolumn{2}{|l|}{ Total geral } & $\begin{array}{l}186 \\
(100 \%)\end{array}$ & $100 \%$ & $100 \%$ \\
\hline
\end{tabular}

O grupo incongruente foi representado por 103 alunos ( $55.4 \%$ da amostra), dentre os quais 57 do género masculino ( $55.3 \%$ do grupo incongruente e

$54.8 \%$ da amostra masculina) e 46 do género feminino ( $44.7 \%$ do grupo incongruente e $56.1 \%$ da amostra feminina).

A grande maioria dos alunos incongruentes denotou percepção positiva em relação à sua habilidade, mantida acima das expectativas projectadas pelos professores, na medida em que $84.5 \%$ dos alunos deste grupo $(n=87)$ se perceberam acima do nível de habilidade esperado pelo professor, enquanto $15.5 \%$ $(n=16)$ expressaram percepções abaixo das expectativas dos professores.

Considerando que o desempenho do aluno se constitui tanto numa fonte de impressões para a formulação das expectativas dos professores, quanto influencia as representações formuladas pelos alunos sobre a sua competência perante a classe, cruzámos os dados de auto-relato de professores e alunos com o desempenho final na unidade experimental de ensino e, posteriormente, comparámo-los. A actividade de salto em altura possui uma característica claramente classificatória. A forma como decorreu a avaliação dos alunos no teste de final de unidade também poderia ter contribuído para o estabelecimento de um ambiente deveras comparativo e classificatório. Assim, interessava conhecer se o auto-relato da competência percebida pelo aluno correspondia ao desempenho obtido mediante tais condições. A média global de desempenho dos alunos foi de $112.6 \mathrm{~cm}(\mathrm{SD}=17.4$ e amplitude entre 70 e $155 \mathrm{~cm})$. A comparação do desempenho do grupo congruente $(113.85 \mathrm{~cm}, \mathrm{SD}=18,2)$ e incongruente $(111.55 \mathrm{~cm}$, $\mathrm{SD}=16.7)$ não indicou diferenças significativas. Entretanto, quando comparadas as médias obtidas pelos alunos congruentes-alto $(122.50 \mathrm{~cm}$, $\mathrm{SD}=16.3)$ e congruentes-baixo $(95.00 \mathrm{~cm}$, $\mathrm{SD}=16.4)$, o teste $t$ indica diferenças significativas $(t=-4.67, \mathrm{p}<.001)$. As diferenças não foram significativas entre os incongruentes-alto $(111.09 \mathrm{~cm}$, $\mathrm{SD}=15.2)$ e incongruentes-baixo $(114.06 \mathrm{~cm}$, $\mathrm{SD}=23.4)$.

Com a intenção de verificarmos a congruência das percepções pessoais dos alunos e expectativas docentes com o desempenho do aluno, procedemos à classificação do desempenho obtido pelos alunos no final da unidade experimental de ensino. Com efeito, foram calculados os quartis com base no intervalo dos escores registados no teste final. Ao primeiro quartil, denominado posto 1 , corresponderam os resultados inferiores produzidos no teste (70 a 100 $\mathrm{cm}$ para todos os grupos), enquanto ao último quartil, denominado posto 2 , corresponderam os resultados superiores (125 a $155 \mathrm{~cm}$ para o grupo congruente; 120 a $150 \mathrm{~cm}$ para o grupo incongruente). Era suposto que, se as percepções dos alunos e as expectativas dos professores estivessem relacionadas com o desempenho do aluno, então o desempenho dos alunos de alta competência percebida e as expectativas docentes mais elevadas deveriam enquadrarse no posto 2 e, segundo a mesma lógica, os resultados dos alunos de baixa competência percebida e as expectativas docentes mais baixas deveriam se enquadrar no posto 1.

No grupo congruente $(n=83)$, em $42.2 \%$ dos casos a auto-percepção dos alunos e a expectativa dos professores foram coerentes com o desempenho na unidade experimental de ensino, i.e., a análise denota concordância entre as expectativas docentes, a competência percebida pelo aluno e o desempenho académico. A análise dos alunos alvo de baixa expectativa do professor revelou que $60 \%$ apresentaram desempenho ao nível do primeiro quartil, enquanto $10 \%$ ao nível do último quartil. Entre os alunos que foram 
alvo de expectativas elevadas por parte dos professores $(n=36), 44 \%$ apresentaram desempenho ao nível do último quartil, enquanto $5.6 \%$ ao nível do primeiro quartil. O facto de mais de metade dos alunos deste grupo não apresentar desempenho compatível com o nível de competência percebida e, assim mesmo, manter alta a sua percepção de competência, pode indiciar a possível influência das expectativas dos professores, neste caso, transmitidas maioritariamente através de estratégias de gestão do clima relacional com estes alunos.

Ainda que a correspondência directa entre as expectativas docentes e percepções discentes não se estabeleça no grupo incongruente, analisámos em que medida as representações de alunos e professores denotavam acordo com o desempenho final. A análise mostrou que as expectativas dos professores coincidiram com o desempenho final em $36.9 \%$ dos casos, sendo mais expressiva a correspondência entre as baixas expectativas e os desempenhos mais baixos. Isto talvez possa ser explicado pelo facto do professor identificar com maior clareza os alunos menos habilidosos.

A análise da correspondência da competência percebida pelo aluno incongruente com o desempenho permitiu constatar que $42.7 \%$ dos alunos apresentaram desempenho compatível com o nível de competência percebida. Entretanto, quando se analisa o resultado exclusivamente sob a perspectiva das classes de alunos de alta e baixa percepção de competência, verificamos que $50 \%$ dos alunos de baixa competência percebida produziram resultados correspondentes com o posto 1. Já entre os alunos de alta percepção de competência a correspondência ocorreu na proporção de $41.9 \%$. Assim, se o grupo incongruente de baixa percepção de competência foi mais criterioso que o seu oposto, colocamos a hipótese de ter sido influenciado em maior grau pelo resultado do seu desempenho, comparativamente aos restantes colegas de turma.

Como procedimento final, procurámos verificar as relações existentes entre a expectativa dos professores e a competência percebida pelos alunos, bem como entre estas e o desempenho na unidade experimental de ensino. Considerando toda a amostra, verificámos correlações significativas entre as expectativas dos professores e a competência percebida dos alunos $(\mathrm{r}=.34, \mathrm{p}<.01)$, entre as expectativas dos professores e o desempenho dos alunos $(\mathrm{r}=.33$, $\mathrm{p}<.01$ ), e entre a competência percebida dos alunos e o seu desempenho $(r=.30, p<.01)$. Ao analisar apenas o grupo de alunos congruentes, além da relação que já é inerente entre as expectativas dos professores e as percepções dos alunos, verificámos que, quer as expectativas dos professores $(r=.49, \mathrm{p}<.01)$ quer a competência percebida dos alunos $(\mathrm{r}=.50$, $\mathrm{p}<.01$ ), denotam relações significativas com o desempenho final na unidade experimental de ensino. Entretanto, a análise independente dos grupos congruentes alto e baixo, apesar de denotar relações positivas, não demonstrou serem significativas. Isto pode ser devido à expressão de congruência face ao quantitativo de alunos, principalmente entre os congruentes-baixo, não ter sido suficiente para fazer emergir a significância estatística. A auto-percepção dos alunos incongruentes-baixo $(n=16)$ correlacionou-se significativamente com a expectativa dos professores $(r=.60, p<.01)$, indicando a tendência de evolução dos níveis de competência percebida dos alunos à medida que aumentou a expectativa dos professores. Finalmente, entre os incongruentes-alto $(\mathrm{n}=87)$ pudemos verificar de forma mais expressiva a relação significativa da competência percebida com a expectativa dos professores $(\mathrm{r}=.51, \mathrm{p}<.01)$ do que com o resultado de desempenho $(\mathrm{r}=.22, \mathrm{p}<.03)$.

\section{DISCUSSÃO}

Rememore-se que as expectativas radicadas nas impressões percebidas pelo professor influenciam a sua forma de estruturar e gerir a dimensão pedagógica do ensino. Isto tem consequências para as oportunidades de aprendizagem oferecidas aos alunos, bem como para o clima interactivo. Portanto, antes de discutirmos a expressão quantitativa dos dados, faz sentido interpretá-los em consonância com a observação do contexto em que decorreu o ensino e do comportamento do professor durante as aulas.

$\mathrm{Na}$ unidade experimental de ensino, em geral, os professores comportaram-se de modo a motivar todos os alunos, independentemente das expectativas sobre a sua competência. Entretanto, observou-se a quase totalidade de contextos massivos de aprendizagem, embora ajustando as condições de realização da tarefa para os alunos sobre os quais os professores ali- 
mentavam baixas expectativas. Apesar do conteúdo contribuir para o estabelecimento de um ambiente altamente classificatório, foi evidente que os professores procuraram estabelecer um clima positivo, transmitindo confiança aos alunos durante as aulas. Em geral, independentemente do nível de habilidade, os alunos receberam muitos elogios. Os professores incentivaram mais os alunos que demonstravam maiores dificuldades, tendo mesmo, em algumas oportunidades, valorizado mais o esforço que propriamente o resultado do desempenho. Outra atitude manifesta dos docentes, no sentido de valorizar o envolvimento do aluno nas tarefas, foi destacar para a turma os movimentos correctos que alguns alunos 'menos habilidosos' realizavam. O critério de êxito foi flexibilizado de modo a transparecer para os alunos 'menos habilidosos' o alcance dos objectivos propostos. Ao baixar o nível de exigência, as tarefas eram pouco atractivas para os alunos 'mais habilidosos', os quais reagiam com sarcasmo e desinteresse face à inadequação do critério de êxito ao seu nível de competência. Em resposta, apesar de algumas vezes criticarem tal atitude, os professores privilegiaram o estabelecimento de interacções positivas com estes alunos, relevando a sua competência na realização das tarefas através de incentivos e fornecimento de pistas visando o progresso do desempenho.

A análise dos resultados permite a interpretação sob duas perspectivas. A primeira, relativa aos efeitos do desempenho e da comparação social sobre a competência percebida pelos alunos, reflectindo no recurso ao parâmetro normo-social para ajuizar o próprio desempenho em relação aos companheiros de classe. Coerente com a teoria, as impressões retidas pelos professores os induzem a produzir contextos de ensino e oportunidades de aprendizagem compatíveis com o que esperam dos alunos. Como afirma Palardy (18), a proposição de uma profecia é, também, um acto de criação das condições para que ela se realize.

Neste estudo, quase metade dos alunos manifestaram percepções congruentes com as expectativas dos professores. Este resultado é similar ao obtido no estudo de Bibik (2), no qual a auto-percepção de $50 \%$ dos alunos correspondeu às expectativas do professor. A correspondência entre as percepções dos alunos, as expectativas dos professores e a rela- ção de ambas com o desempenho realizado pelo aluno sugere uma dinâmica similar ao modelo referido por Martinek (13), ao abordar o efeito pigmalião no ensino em educação física.

O clima, o feedback, as informações e suporte fornecido aos alunos aparecem como elementos que irradiam as expectativas dos professores aos alunos (24, 13). Neste estudo, os factores que podem ter contribuído para a manutenção de percepções congruentes pelos alunos de alta competência percebida foram o clima estabelecido pelos professores e o suporte a eles fornecido, mesmo que informal. Os alunos congruentes de baixa competência percebida, apesar de incentivados perante a turma, receberam feedback público sobre a sua prestação, facto que pode ter contribuído para perceberem o comportamento do professor como forma de incentivo à prática mas, face à exteriorização de suas deficiências e à assumpção de critérios normo-sociais no juízo sobre a própria performance, quer em termos de realização do gesto técnico quer em termos de desempenho quantitativo (altura saltada), também poderá ter contribuído para a ponderação sobre as capacidades pessoais.

Em geral, os professores justificaram a estratégia de acção como modo de manter indistintamente todos os alunos motivados. Entretanto, outros estudos $(12,19,15)$ indicam que os alunos nem sempre interpretam as ocorrências de ensino consoante as intenções dos professores ou da mesma forma entre si. A frequência e intensidade das interacções, suporte, felicitações, concessão de privilégios e severidade das avaliações são interpretadas pelos alunos como fontes de alta e baixa expectativa projectadas pelos professores (7).

Outro resultado relevante a destacar diz respeito aos alunos que relataram percepção de competência dissonante com o próprio desempenho, i.e., alunos de baixa competência percebida. Apesar de realizarem rendimentos na média da turma ou mesmo acima da média, mantiveram tal percepção. Por outro lado, os alunos de alta competência percebida mantiveram alta a sua percepção, apesar do desempenho em níveis inferiores. Portanto, uma parcela considerável dos alunos manifestou percepções mais congruentes com as expectativas dos professores do que com os resultados do seu desempenho. Considerando que, a despeito do desempenho, as expectativas docentes e 
as percepções pessoais dos alunos tenham se apresentado congruentes, é possível que a unidade experimental de ensino não tenha sido longa o suficiente para influenciar as percepções pessoais dos alunos, face aos resultados verificados. Ao mesmo tempo, isto permite evidenciar quão consistente e permanente podem se tornar as crenças sobre a auto-competência retida pelos alunos, sobrepujando mesmo o desempenho manifesto.

Por fim, a concordância e relações verificadas da avaliação dos professores e auto-percepção dos alunos com as realizações na unidade experimental de ensino, revelaram tanto a competência do professor quanto a competência de uma parte expressiva de alunos no ajuizamento do desempenho académico. Em 40\% dos casos, a aferição dos professores correspondeu ao desempenho demonstrado pelos alunos no final da unidade experimental de ensino. Ainda que se esperasse valores mais substantivos, deve-se ter em conta que o conteúdo fugia ao padrão de actividades desenvolvidas nas aulas de educação física, onde prevalece o ensino de jogos e actividades desportivas colectivas. Portanto, a avaliação dos professores foi condicionada pela mobilização de informações, baseadas em parâmetros distintos do habitual, na projecção da competência dos alunos no conteúdo de salto em altura.

Isto ficou evidente nas questões colocadas pelos professores no momento da avaliação, oportunidade em que expressaram dúvidas quanto ao juízo formulado face à novidade do conteúdo.

Foi considerável a proporção de alunos que reportaram níveis de habilidade compatíveis com o desempenho realizado na unidade experimental de ensino. Estes resultados foram notavelmente influenciados pelos alunos que reportaram alta percepção de competência. No estudo de Bibik (2), os alunos incongruentes-alto demonstraram forte crença nas suas capacidades e, por isso, recorreram menos à comparação social na formulação da própria competência. Muitas vezes justificaram a falta de atenção do professor, alegando não precisar de feedback.

Se uma parcela expressiva de alunos de diferentes níveis de habilidade $(42.5 \%)$ demonstrou coerência do sentimento de competência com o desempenho, podemos realçar a importância de se considerar o auto-relato dos alunos sobre a própria competência na tomada de decisões pedagógicas (8), bem como no processo de avaliação escolar (25).

\section{CONCLUSÃO}

Os resultados ratificam a complexidade inerente ao processo ensino-aprendizagem. Isto ficou evidente nos indícios de que tanto as expectativas docentes quanto o desempenho podem ter influenciado a percepção de competência dos alunos.

Em resposta às questões iniciais colocadas neste estudo, cerca de metade da amostra relatou percepções congruentes com as expectativas do professor. Além disso, considerando o conjunto amostral, foi significativa a relação entre as expectativas docentes e a percepção de competência dos alunos. Verificouse, ainda, que a auto-percepção de alguns alunos congruentes alto e baixo se relacionou com a expectativa de seus professores, muito embora tenham apresentado desempenho abaixo ou acima do que seria suposto, respectivamente. A expressão desta correspondência não pode ser negligenciada, principalmente por ocorrer no ambiente escolar que deve primar por promover sentimentos positivos e a inclusão de todos os alunos no processo educativo. Parece não existir dúvida de que o desempenho também serviu de parâmetro para os alunos formularem as suas percepções. Cerca de $40 \%$ dos alunos, independentemente do grau de congruência, denotaram percepções coerentes com o desempenho final na unidade experimental de ensino. Os alunos de baixa percepção de competência poderão ser mais influenciados por critérios normativos, com fortes indícios de que a comparação social em classe tenha servido de parâmetro para a maioria no ajuizamento da própria competência.

O professor constituiu-se numa boa fonte de informação sobre a competência do aluno, principalmente se tratando de ter ajuizado a sua habilidade com antecedência e num conteúdo pouco comum no programa da disciplina. As suas expectativas foram mais congruentes com o desempenho dos alunos de baixa percepção de competência. Este apuramento pode ser útil no momento de planear e operacionalizar tarefas ao nível de competência dos alunos.

As implicações práticas destes resultados têm sido enfaticamente ressaltadas pela literatura, demonstrando que os alunos podem constituir uma importante fonte de informação para uma melhor compreensão do processo ensino-aprendizagem. O que os alunos pensam pode ser muito importante para 
os professores compreenderem os mecanismos que engendram as suas aprendizagens. O sentimento do aluno sobre a sua competência é fundamental, na medida em que, em alguns casos, aquilo que ele pensa ser capaz de fazer pode influenciar o comportamento face às tarefas propostas.

Por outro lado, o conhecimento que o professor possui sobre os seus alunos favorece a estruturação do ensino, de forma a permitir-lhes experimentar o sucesso com constância na disciplina. A literatura tem ressaltado a importância do clima para o estabelecimento de um ambiente favorável às aprendizagens e dirigido ao incentivo de sentimentos positivos de competência nos alunos. Entretanto, a acção do professor deve estar baseada na gestão eficaz da tarefa, a fim de potencializar a aprendizagem dos alunos, pois as suas crenças são formadas a partir da frequência de oportunidades de participação, associada com o sentimento de sucesso que estas lhes garantem. Estas acções frutificarão, resultando em maior motivação e persistência dos alunos para concretizar as aprendizagens.

\section{AGRADECIMENTO}

Agradecemos à CAPES - Brasil o apoio concedido durante a realização deste trabalho.

\section{CORRESPONDÊNCIA}

\section{Carlos Januário}

Faculdade de Motricidade Humana

Departamento de Ciências da Educação

Estrada da Costa

1495-688 Cruz Quebrada

Portugal

cjanuario@fmh.utl.pt 


\section{REFERÊNCIAS}

1. Bandura A (1994). Self-efficacy. In V. S. Ramachaudran (Ed.) Encyclopedia of Human Behavior (Vol. 4). New York: Academic Press, 71-81.

2. Bibik JM (1999). Factors influencing college students' selfperceptions of competence in beginning Physical Education classes. Journal of Teaching in Physical Education, 18, 255-276.

3. Bibik JM (1993). Pedagogical considerations regarding perceptions of dance competence. Journal of Teaching in Physical Education 12(3): 266-285.

4. Carmo H, Ferreira MM (1998). Metodologia da investigação: Guia para auto-aprendizagem. Lisboa: Universidade Aberta.

5. Clark CM, Peterson P (1986). Teachers' thought processes. In M. Wittrock (Ed.) Handbook of Research on Teaching (3 ${ }^{\text {rd }}$ ed.). New York: Macmillan, 255-296.

6. Flegner AJ, Dias J (1995). Pesquisa e metodologia: Manual completo de pesquisa e redação. Rio de Janeiro: Ministério do Exército.

7. Gagnon J, Martel D, Grenier J, Pelletier-Murphy J, Dumont $S$ (1995). Pygmalion au gymnase: Une réalité perceptible par les élèves. Paper presented at the VIèmes Journées Internationales d'Automne de l'ACAPS. Retrieve in http://caratome.free.fr/Publications/Pygmalion.htm.

8. Graham G (1995). Physical Education through students' eyes and students' voices: Implications for teachers and researchers. Journal of Teaching in Physical Education 14, 478-482.

9. Lee AM (1997). Contributions of research on student thinking in Physical Education. Journal of Teaching in Physical Education 16, 262-277.

10. Lee AM, Carter JA, Xiang P. (1995). Children's conceptions of ability in Physical Education. Journal of Teaching in Physical Education 14, 384-393.

11. Lee AM, Fredenburg K, Belcher D, Cleveland N (1999). Gender differences in children's conceptions of competence and motivation in Physical Education. Sport, Education and Society 4(2): 161-174.

12. Lee AM, Solmon MA (1992). Cognitive conceptions of teaching and learning motor skills. Quest 44, 57-71.

13. Martinek TJ (1981). Pygmalion in the gym: A model for the communication of teacher expectations in Physical Education. Research Quarterly for Exercise and Sport 52(1), 58-67.

14. Martinek TJ (1988). Confirmation of a teacher expectancy model: Student perception and causal attributions of teaching behaviors. Research Quarterly for Exercise and Sport 59, 118-126.

15. Martinek TJ (1989). Children's perceptions of teaching behaviors: An attributional model for explaining teacher expectancy effects. Journal of Teaching in Physical Education 8, 318-328.

16. Nicholls J (1984). Achievement motivation: conceptions of ability, subjective experience, task choice, and performance. Psychological Review 91, 328-346.

17. Onofre M (2003). Modelos de investigação sobre o ensino da Educação Física: Da antinomia à coexistência. Boletim da Sociedade Portuguesa de Educação Física 24/25, 63-72.

18. Palardy JM (1969). What teachers believe-what children achieve. Elementary School 69, 370-374.

19. Piéron M (1982). Behaviors of low and high achievers in physical education classes. In M. Piéron \& J. Cheffers
(Eds.) Studying the Teaching in Physical Education. Liege: AIESEP, 53-60.

20. Pimentel JN (1986). Análise do comportamento dos alunos mais dotados em diferentes jogos desportivos colectivos. Dissertação de mestrado. ISEF, UTL.

21. Rosenthal R, Babad EY (1985). Pygmalion in the gymnasium. Educational Leadership 43(1): 36-39.

22. Solmon MA, Carter JA (1995). Kindergarten and first grade students' perceptions of physical education in one teacher's classes. Elementary School Journal 95, 355-365.

23. Sparkes A (1991). Toward understanding, dialogue, and polyvocality in the research community: Extending the boundaries of the paradigms debate. Journal of Teaching in Physical Education 10, 103-133.

24. Tauber RT (1998). Good or bad, what teachers expect from students they usually get. ERIC Clearinghouse on Teaching and Teacher Education (ERIC Document Reproduction Service No. ED 426985).

25. Veal ML, Compagnone N (1995). How sixth grades perceive effort and skill. Journal of Teaching in Physical Education 14, 431-444.

26. Weinstein R, Marshall H, Brattesani K, Middlestadt S (1982). Student perceptions of differential teacher treatment in open and traditional classrooms. Journal of Educational Psychology 74, 678-692.

27. Weiss MR, Ebbeck V, Horn TS (1997). Children's self-perceptions and sources of physical competence information: A cluster analysis. Journal of Sport and Exercise Psychology $19,52-70$.

28. Weiss MR (2000). Motivating kids in physical activity. President's Council on Physical Fitness and Sports Research Digest. Retrieved 26/maio, 2002, from the World Wide Web: http://www.fitness.gov/digest900.pdf

29. Xiang P, Lee AM (1998). The development of self-perceptions of ability and achievement goals and their relations in physical education. Research Quarterly for Exercise and Sport 69, 231-241. 